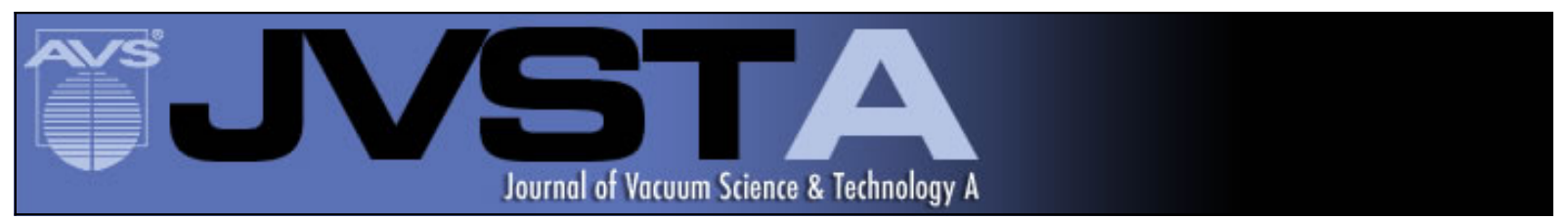

\title{
Growth of single and bilayer graphene by filtered cathodic vacuum arc technique
}

A. K. Kesarwani, O. S. Panwar, S. R. Dhakate, R. K. Rakshit, V. N. Singh, Atul Bisht, and Ashish Kumar

Citation: Journal of Vacuum Science \& Technology A 34, 021504 (2016); doi: 10.1116/1.4936258

View online: http://dx.doi.org/10.1116/1.4936258

View Table of Contents: http://scitation.aip.org/content/avs/journal/jvsta/34/2?ver=pdfcov

Published by the AVS: Science \& Technology of Materials, Interfaces, and Processing

\section{Articles you may be interested in}

Probing graphene defects and estimating graphene quality with optical microscopy

Appl. Phys. Lett. 104, 043101 (2014); 10.1063/1.4863080

Few layer graphene synthesized by filtered cathodic vacuum arc technique

J. Vac. Sci. Technol. B 31, 040602 (2013); 10.1116/1.4813762

Local solid phase growth of few-layer graphene on silicon carbide from nickel silicide supersaturated with carbon J. Appl. Phys. 113, 114309 (2013); 10.1063/1.4795501

Graphene layer growth on silicon substrates with nickel film by pulse arc plasma deposition Appl. Phys. Lett. 101, 163109 (2012); 10.1063/1.4761474

Wafer-scale epitaxial graphene growth on the Si-face of hexagonal SiC (0001) for high frequency transistors J. Vac. Sci. Technol. B 28, 985 (2010); 10.1116/1.3480961

\section{HDDEN}

\section{Instruments for Advanced Science}

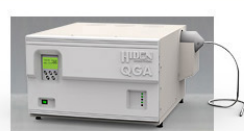

Gas Analysis

dynamic measurement of reaction gas streams cataysis and thermal analysis molecular beam studies

dissolved species probes

, fermentation, environmental and ecological studies

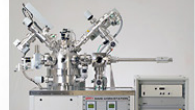

Surface Science

, UHVTPD

SIMS elemental imaging - surface mapping

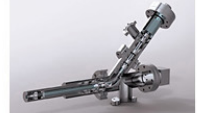

Plasma Diagnostics plasma source characterization tch and deposition process rection kinetic studies , analysis of neutral and radical species

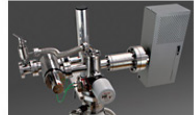

Vacuum Analysis ' partial pressure measurement and control of process gases reactive sputter process contro , vacuum diagnostics vacuum coating process monitoring 


\title{
Growth of single and bilayer graphene by filtered cathodic vacuum arc technique
}

\author{
A. K. Kesarwani and O. S. Panwara) \\ Polymorphic Carbon Thin Films Group, Physics of Energy Harvesting Division, CSIR-National Physical \\ Laboratory, Dr. K. S. Krishnan Road, New Delhi 110012, India and Academy of Scientific and Innovative \\ Research (AcSIR), CSIR Campus, New Delhi 110012, India
}

\section{S. R. Dhakate}

Physics and Engineering of Carbon Materials, Division of Materials Physics and Engineering, CSIR-National Physical Laboratory, Dr. K. S. Krishnan Road, New Delhi 110012, India and Academy of Scientific and Innovative Research (AcSIR), CSIR Campus, New Delhi 110012, India

\section{R. K. Rakshit}

Quantum Phenomena and Applications Group, CSIR-National Physical Laboratory, Dr. K. S. Krishnan Road, New Delhi 110012, India and Academy of Scientific and Innovative Research (AcSIR), CSIR Campus, New Delhi 110012, India

\begin{abstract}
V. N. Singh
Electron and Ion Microscopy, Sophisticated and Analytical Instruments, CSIR-National Physical Laboratory, Dr. K. S. Krishnan Road, New Delhi 110012, India and Academy of Scientific and Innovative Research (AcSIR), CSIR Campus, New Delhi 110012, India

\section{Atul Bisht}

Polymorphic Carbon Thin Films Group, Physics of Energy Harvesting Division, CSIR-National Physical Laboratory, Dr. K. S. Krishnan Road, New Delhi 110012, India and Academy of Scientific and Innovative Research (AcSIR), CSIR Campus, New Delhi 110012, India
\end{abstract}

Ashish Kumar

Polymorphic Carbon Thin Films Group, Physics of Energy Harvesting Division, CSIR-National Physical Laboratory, Dr. K. S. Krishnan Road, New Delhi 110012, India

(Received 25 August 2015; accepted 9 November 2015; published 30 November 2015)

The authors present a viable process to grow the high quality graphene films with control over number of layers by the filtered cathodic vacuum arc (FCVA) technique. In the FCVA process, the different carbon concentrations can be controlled by precisely tuning the arc time (1-4 s). The arc generated carbon was deposited on the nickel catalyst at $800^{\circ} \mathrm{C}$, annealed for $10 \mathrm{~min}$, and cooled down to room temperature in the presence of hydrogen gas, resulting in the graphene films with control over number of layers. Prior to arcing, hydrogen etching of nickel was carried out to clean the surface of the substrate. A growth model to prepare the high quality graphene has also been proposed. The as-grown graphene films were transferred to different substrates and are characterized by Raman spectroscopy, optical microscopy, high resolution transmission electron microscopy, and atomic force microscopy to determine the number of layers present in these films. Raman spectra of the prepared graphene films exhibit change in the $G$ peak position from 1582.4 to $1578.1 \mathrm{~cm}^{-1}$, two-dimensional (2D) peak shifts from 2688.5 to $2703.8 \mathrm{~cm}^{-1}$, the value of $\mathrm{I}_{2 \mathrm{D}} / \mathrm{I}_{\mathrm{G}}$ increased from 0.38 to 3.82 , and the full width at half maxima of $2 \mathrm{D}$ peak changed from 41 to $70 \mathrm{~cm}^{-1}$, for different layers of graphene films. The high resolution transmission electron microscopy image revealed that the graphene films prepared for 1 and $2 \mathrm{~s}$ arc times have single and bi- or trilayered structures, respectively. @ 2015 American Vacuum Society. [http://dx.doi.org/10.1116/1.4936258]

\section{INTRODUCTION}

Graphene has generated extensive enthusiasm in the research community since it was first isolated in 2004 by Novoselov et al. ${ }^{1}$ from graphite. Due to its intriguing properties such as high carrier mobility, chemical stability, excellent mechanical strength, and high optical transparency, ${ }^{2-4}$ it has been assured as a promising material for optical, electronic, and flexible devices. ${ }^{5-7}$ Initially, micromechanical exfoliation of highly oriented pyrolytic graphite was used to produce

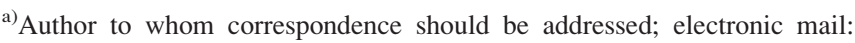
ospanwar@mail.nplindia.ernet.in
}

single layer graphene. But, the method is uncontrollable and as well as unsuitable for the large scale up production. Later on, chemical vapor deposition (CVD) and reduction in graphene oxide were established as methods to synthesize graphene on a large scale. ${ }^{8,9}$ In addition, both the CVD and solid carbon sources can be used to synthesize graphene films with controlled thickness with the help of transition metal catalyst such as $\mathrm{Pt}, \mathrm{Ru}, \mathrm{Cu}$, and $\mathrm{Ni}^{10-12}$ Furthermore, the substantial variation in the graphene properties has been observed due to the thickness fluctuations even for the single layer graphene. Therefore, control over the growth of graphene on the transition metal substrates is a crucial issue, and it necessitates a fundamental understanding of the growth mechanism at the 
atomic level. ${ }^{13}$ In the CVD process, an optimized mixture of hydrocarbon and hydrogen gas is used to produce good quality graphene. ${ }^{14}$ Specifically, $\mathrm{Cu}$ and $\mathrm{Ni}$ are used frequently to grow graphene films. But, the growth kinetics and mechanism of growth on these metals are dissimilar due to the difference in the solubility of carbon $(<0.001$ at. $\%$ in $\mathrm{Cu}$ and $>0.1$ at. \% in $\mathrm{Ni}){ }^{15}$ Moreover, the growth of graphene on Ni catalyst has been found to be a two-step process, which involves the dissolution of carbon atoms into the Ni substrate at higher temperatures, followed by the diffusion and precipitation onto the $\mathrm{Ni}$ surface to form the graphene layers during cooling of the substrate. In contrast to above, in the case of $\mathrm{Cu}$ catalyst, surface diffusion of carbon atoms is understood to be more feasible growth process to obtain monolayer graphene on $\mathrm{Cu}$ substrate. Furthermore, it has been observed that the hydrogen plays an important role in the formation of graphene on catalytic substrates ${ }^{16}$ by controlling the surface reaction. It is also utilized for surface cleaning and crystallization of the catalytic substrates prior to the graphene growth. Thus, in order to understand the dependence of graphene synthesis under various growth conditions and to achieve better control over the graphene film thickness, a primary insight into the growth mechanisms is imperative. Recently, our group has reported the synthesis of few layered graphene by the filtered cathodic vacuum arc (FCVA) technique. ${ }^{17,18}$

The FCVA technique is a plasma based technique, which has been recognized and developed as a worthy and versatile technique for the fabrication of metal thin films. Additionally, the potential application of the FCVA in the industry is seen as a potential method for fabricating high quality hard and decorative coatings of metal oxides, ceramics, diamond like carbon, tetrahedral amorphous carbon, TiN, etc. ${ }^{19-22}$ It is a low voltage, high current plasma discharge that takes place between the two conducting electrodes. The process is carried out either in vacuum or in low pressure gas environment $\left(\mathrm{O}_{2}\right.$ or $\left.\mathrm{N}_{2}\right)$ in the reactive mode. Accordingly, the respective properties of thin films deposited by the FCVA technique can be controlled and modulated by applying various process parameters (gas pressure, substrate temperature, and substrate bias). ${ }^{23,24}$ Fujita et al. ${ }^{25}$ have utilized the pulse arc plasma deposition technique to grow graphene layers by controlling the deposition rate $(0.1 \mathrm{~nm} / \mathrm{s})$. Multiple pulses were initiated with a pulse rate of 1 pulse/s, which led to the deposition of the film at required thickness. Therefore, the comprehension, controllability, reliability, and reproducibility of the FCVA technique to synthesize various thin films has inspired us to utilize this technique for the growth of high quality single and multilayer graphene.

In this paper, the FCVA technique has been used to synthesize single and multilayer graphene by solid carbon source. The growth mechanism of graphene has been discussed, and a model is proposed. The structural and optical properties of graphene were characterized, and the results are discussed in detail.

\section{EXPERIMENT}

For the growth of few layer graphene, nickel thin films $(300 \mathrm{~nm})$ deposited at $\mathrm{SiO}_{2}(400 \mathrm{~nm}) / \mathrm{Si}(100)$ wafers were used as the catalyst. Ni (nickel) thin films were deposited by DC magnetron sputtering. A high vacuum of $\sim 10^{-8}$ mbars was obtained before sputtering $\mathrm{Ni}$ from $99.99 \%$ pure nickel target. For providing carbon source, high purity graphite as cathode was utilized in the FCVA system. Figure 1 represents the schematic diagram of the FCVA system. Prior to the growth of graphene, the deposition chamber of the FCVA system was evacuated to obtain a base pressure of $\sim 10^{-6}$ mbars, and the arcing parameters were kept as $30 \mathrm{~V}$ voltage and $56 \mathrm{~A}$ arc current. In the previous work, ${ }^{17}$ the deposition rate of this process has been observed as $\sim 1 \mathrm{~nm} / \mathrm{s}$ at $56 \mathrm{~A}$ arc current. The FCVA system used by us has the advantage of pulsating nature and arcing time can be controlled even for $1 \mathrm{~s}$. The various steps to synthesize high quality graphene films having different thicknesses in the pre- and postannealing conditions in the hydrogen gas atmosphere of $\sim 10^{-3}$ mbars has been shown in Fig. 2. The as-grown graphene films on Ni catalyst was spin coated with polymethyl methacrylate (PMMA) layer and treated with a $1 \mathrm{M} \mathrm{FeCl}_{3}$ acid solution to etch the nickel film. After the etching of nickel film, the PMMA/graphene film was treated with deionized water several times and then transferred to the required substrate (quartz or $\mathrm{SiO}_{2} / \mathrm{Si}$ ). To remove the PMMA layer, the sample was treated in a hot acetone bath at $50^{\circ} \mathrm{C}$ for $1 \mathrm{~h}$ and was baked at $200{ }^{\circ} \mathrm{C}$ on a hot plate to enhance the adhesion of the substrates and also to eliminate the polymer residues. In order to determine the number of layers in graphene films, Raman spectroscopy and high resolution transmission electron microscopy (HRTEM) were carried out. Raman spectra were measured at $\sim 5 \mathrm{~mW}$ incident power by a Reninshaw spectrophotometer (microRaman model inVia Reflex) with $514 \mathrm{~nm}$ laser excitation and notch filter cutting at $\sim 50 \mathrm{~cm}^{-1}$ at room temperature. HRTEM experiment was carried out by employing a HRTEM (model Tecnai G2F30 STWIN operating at an electron accelerating voltage of $\sim 300 \mathrm{kV}$ using the field emission electron). The graphene films were lifted on a 200-mesh copper grid of $3.05 \mathrm{~mm}$ diameter. The graphene microstructure was observed by the optical microscope (Zeiss model Axiolab A) having facility for polarized light. The atomic force microscope (AFM) (Nanoscope Veeco-V) was used for the evaluation of height of the sample.

\section{RESULTS AND DISCUSSION}

\section{A. Filtered cathodic vacuum arc}

FCVA is a deposition technique which has distinct properties, such as high ion energy, high ionization rate, and multiple ion charge states. Cathodic arc was initiated by making intimate contact between the high quality graphite cathode and graphite rod as an anode, as shown in Fig. 1. At the arcing point above the surface of the cathode, the arc current is concentrated at a few discrete sites called the cathode spots having a size in the range of 1-10 $\mu \mathrm{m}$ with current density of the order $10^{6}-10^{8} \mathrm{~A} \mathrm{~cm}^{-2} .^{26}$ The cathode spots move rapidly across the surface of the cathode, and the plasma is generated by the arc at these spots due to high pressure. The plasma is composed of a large concentration of carbon ions, and the ion current is a constant fraction of arc current, $\mathrm{I}_{\mathrm{ion}}=\varepsilon \mathrm{I}_{\mathrm{arc}}$, where 


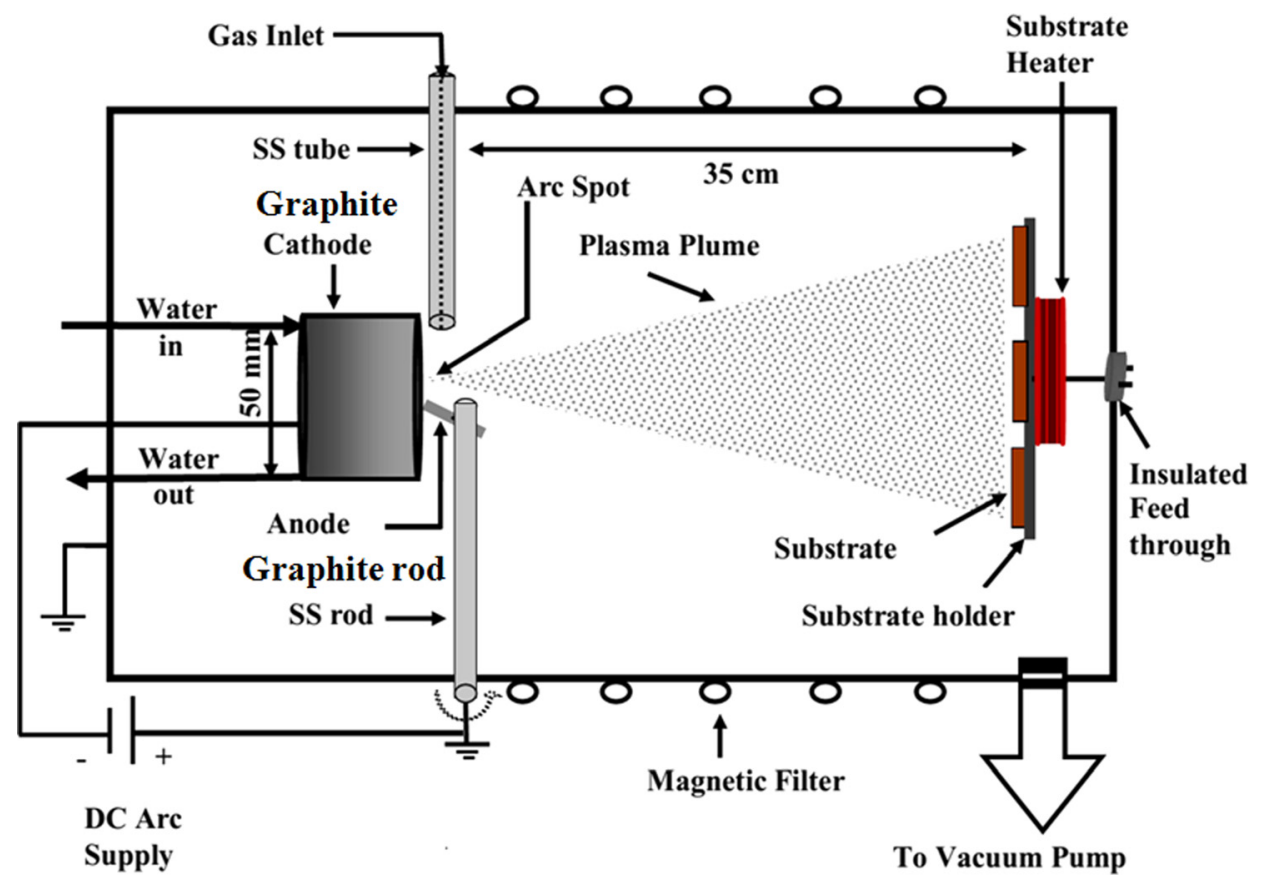

FIG. 1. (Color online) Schematic diagram of the FCVA system.

$\varepsilon$ is in the range of $0.06-0.12$. It has been reported that the ion energy of the carbon ion was found to be $\sim 25 \mathrm{eV}^{27}$ Moreover, the ion surface interaction theory indicates that the high ion energy on the order of $25-100 \mathrm{eV}$ is required to grow a high quality crystalline film. Furthermore, the plasma flux generated at the cathode spots also contains few microdroplets of the cathode material called macroparticles (typically in the range of $0.1-10 \mu \mathrm{m}$ in diameter), which can be filtered by passing plasma flux through the magnetic solenoid. In this work, a linear magnetic filter having a magnetic field of $\sim 0.035 \mathrm{~T}(350 \mathrm{G})$ has been utilized for filtering the graphite macroparticles.

\section{B. Growth model}

Fundamentally, the growth of graphene on nickel occurs due to the temperature dependent solubility of carbon. It has experimentally been shown by various researcheres ${ }^{28}$ that at temperatures below $\sim 500{ }^{\circ} \mathrm{C}$, an atomic layer of nickel carbide forms upon the nickel surface, but as when the temperature is increased, the bond between the nickel and carbon breaks, and the nucleation of graphene begins. Specifically, the controlled growth of graphene by the FCVA technique on the nickel substrate is dependent on the limited carbon concentration generated between the two graphite electrodes by the precise arcing time (1-4s). By the classical molecular dynamics, Wang et al. ${ }^{29}$ have shown the possibility of formation of graphene at different carbon concentrations and temperatures on nickel. They observed that the high carbon concentration may induce the graphene island formation and the island can grow larger by forming more hexagons on the edge with further addition of carbon atoms dynamically. The dissolution of carbon atoms in the nickel at high temperature and diffusing out to the surface during cooling have been proposed for the growth of graphene on nickel. As shown in
Fig. 2, prior to the arcing at $800^{\circ} \mathrm{C}$, hydrogen gas was employed to remove the surface oxide/contaminants (for cleaning the nickel surface) and to increase the grain size of nickel. In the FCVA process, it is assumed that the arc triggered for the least time $(1 \mathrm{~s})$ produces very limited amount of carbon atoms and ions. Thermodynamically, these carbon atoms and ions (at $800^{\circ} \mathrm{C}$ ) dissolve into the nickel and get precipitated at the surface during cooling. Precipitated carbon atoms diffuse at the surface and form dimmers and trimers and nucleation begins as shown in Fig. 3, and subsequently, the carbon island $\left(\mathrm{C}_{\mathrm{n}}\right)_{\mathrm{s}}$ grows. Based on the growth kinetics, $\mathrm{Wu}$ et al. $^{30}$ have shown that the carbon dimmers and trimers have higher probability to associate, energetically, with the hexagonal ring

$$
\begin{aligned}
& \mathrm{H}_{2} \rightarrow 2 \mathrm{H}_{\mathrm{a}}, \\
& \left(\mathrm{C}_{\mathrm{n}}\right)_{\mathrm{s}}+\mathrm{H}_{\mathrm{a}} \rightarrow \text { graphene }+\mathrm{H}_{\mathrm{a}},
\end{aligned}
$$

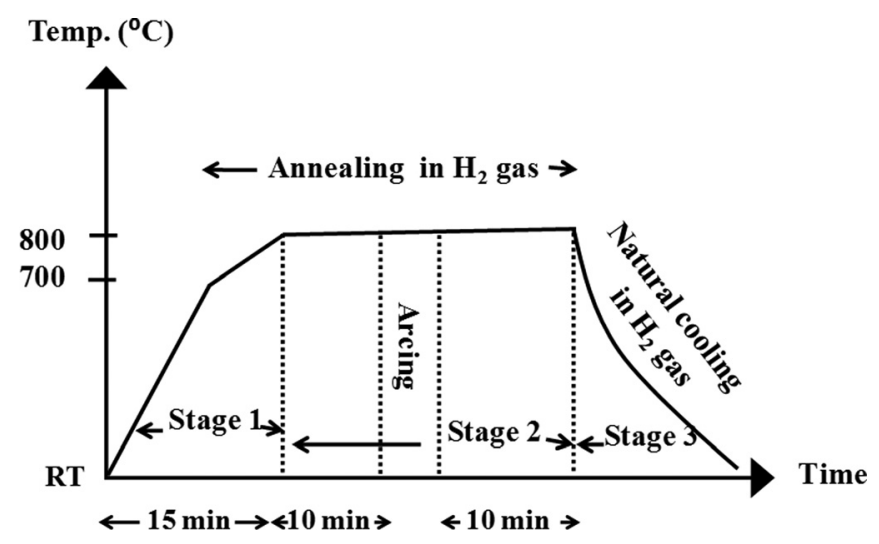

FIG. 2. Plot of different growth processes of graphene films prepared at $800^{\circ} \mathrm{C}$. 


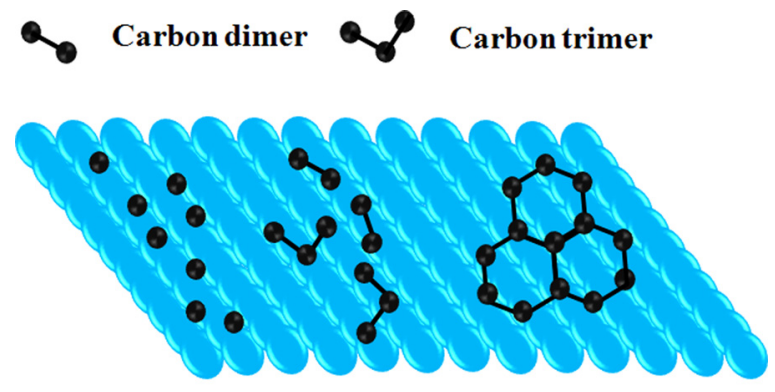

- Carbon atom

FIG. 3. (Color online) Growth model of the graphene film on the nickel substrate.

$$
\text { graphene }+\left(\mathrm{C}_{\mathrm{n}}\right)_{\mathrm{s}}+\mathrm{H}_{\mathrm{a}} \rightarrow \text { graphene }+\mathrm{H}_{\mathrm{a}} .
$$

Furthermore, carbon atoms in the island might be differently bonded $\left(\mathrm{sp}^{3}, \mathrm{sp}^{2}\right)$. During the graphene growth, although hydrogen assumed as an inactive specie, it takes part in many important surface reactions: (1) dissociative chemisorption from the nickel surface, as shown in Eq. (1), (2) atomic hydrogen $\left(\mathrm{H}_{\mathrm{a}}\right)$ can be active in competition of $\left(\mathrm{C}_{n}\right)_{\mathrm{s}}$ deposition/C etching as shown in Eq. (2), and (3) $\mathrm{C} \mathrm{sp}^{3}$ to $\mathrm{sp}^{2}$ transition. Eventually, all these processes led to the growth of a good quality single layer graphene on the nickel surface, as corroborated by the Raman spectra, shown in Fig. 4. Similarly, graphene with controlled number of layers has

been grown by the FCVA process for specific arcing time of $2-4 \mathrm{~s}$, and the results are shown in the HRTEM image of Fig. 5. Moreover, the nickel grain boundary acts as the specific centers for the defect generation in the form of five member rings (MR), seven $\mathrm{MR}$, and $\mathrm{sp}^{3}$ bonded carbon atom. The presence of hydrogen gas at high temperature $\left(800^{\circ} \mathrm{C}\right)$ subdues the defected $(5 \mathrm{MR}, 7 \mathrm{MR})$ bond by generating monoatomic hydrogen, which reacts with other strained bond.

\section{Raman spectroscopy}

Raman spectroscopy, technologically, is a nondestructive tool for the structural characterization of materials. It has been extensively used to investigate the properties of carbon based systems (carbon nanotube, nanographite, graphene, etc.). ${ }^{31}$ In the Raman spectra of graphene, the most prominent features are the $\mathrm{G}$ band appearing at $\sim 1582 \mathrm{~cm}^{-1}$ and the $2 \mathrm{D}$ band at $\sim 2700 \mathrm{~cm}^{-1}$. In the case of disordered graphene, disorder induced D band at $\sim 1350 \mathrm{~cm}^{-1}$ may also appear. Additionally, the $\mathrm{G}$ band generating from the first order Raman scattering process is associated with the doubly degenerate (iTO and LO) phonon mode ( $E_{2 g}$ symmetry) at the BZ center. On the other hand, the $\mathrm{D}$ and the $2 \mathrm{D}$ bands originate from a second order process involving one iTO phonon and one defect for the D band and two iTO phonons near the $\mathrm{K}$ point for the $2 \mathrm{D}$ band, respectively. The $2 \mathrm{D}$ band actually appears due to the intervalley double resonance process near the K point. Furthermore, the position and relative
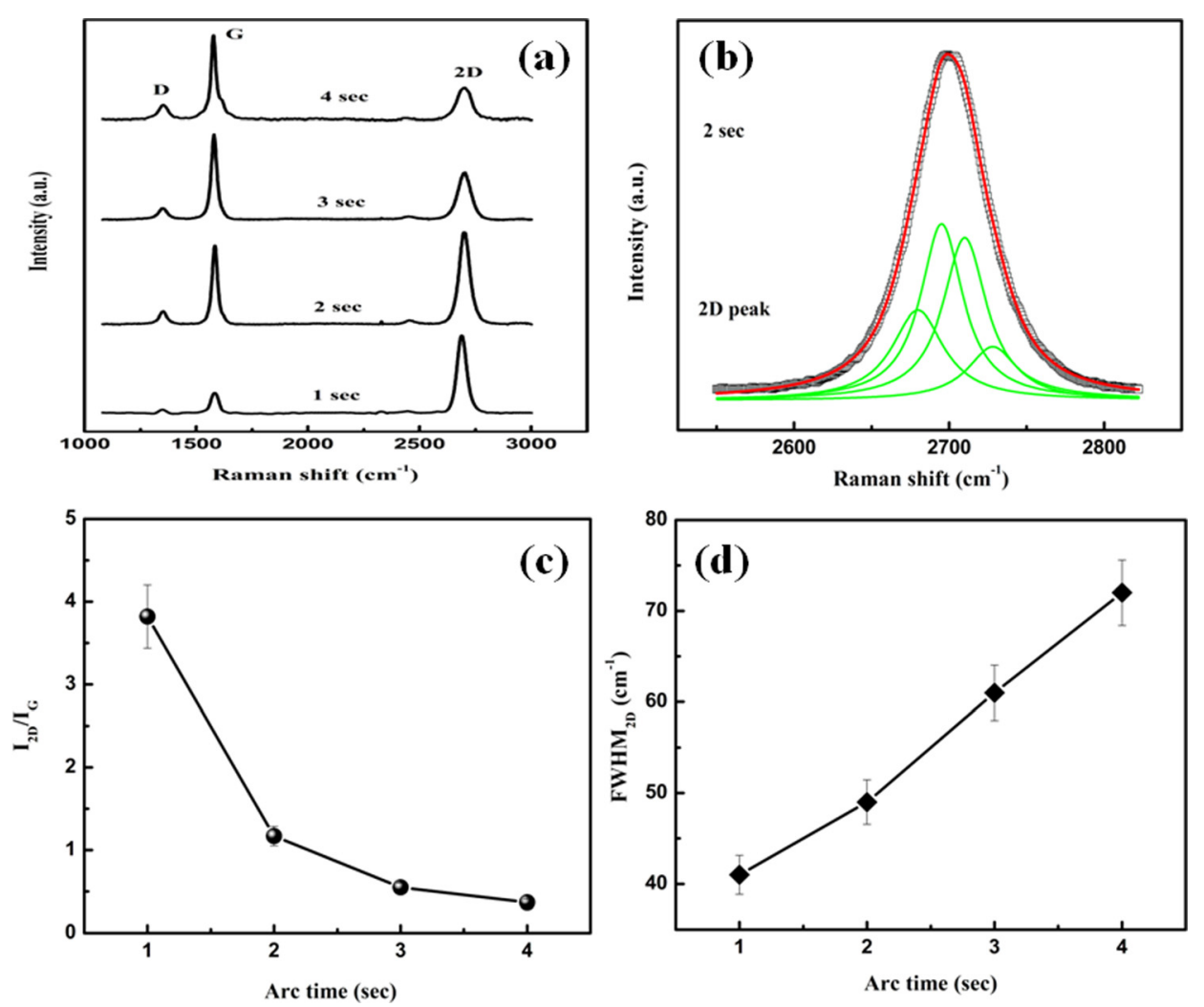

FIG. 4. (Color online) (a) Raman spectra of graphene film prepared at $800^{\circ} \mathrm{C}$ for different arc times, (b) deconvolution of bilayer graphene, (c) value of $\mathrm{I}_{2 \mathrm{D}} / \mathrm{I}_{\mathrm{G}}$ of graphene films, and (d) $\mathrm{FWHM}_{2 \mathrm{D}}$ of graphene films. 


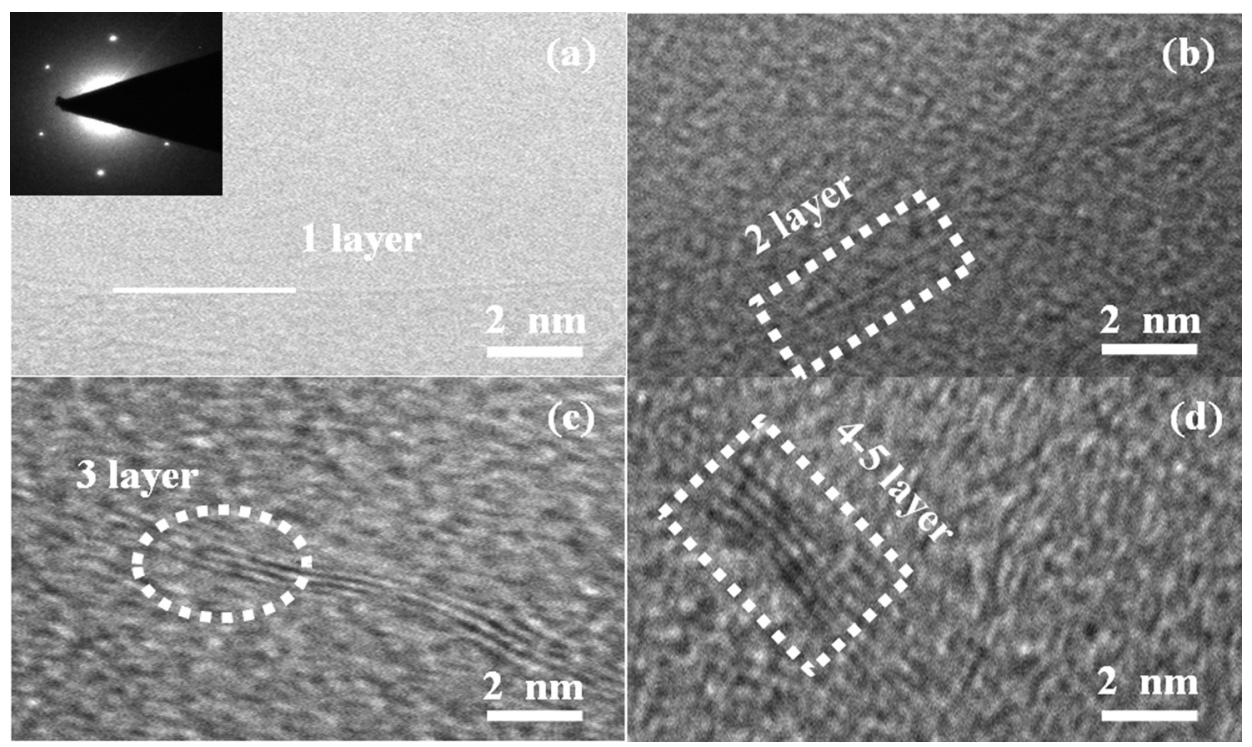

FIG. 5. HRTEM images of graphene films prepared at $800^{\circ} \mathrm{C}$ for different arc times of (a) $1 \mathrm{~s}$, (b) and (c) $2 \mathrm{~s}$, and (d) $3 \mathrm{~s}$.

intensity of different bands provide important insights of the as-grown graphene. Figure 4(a) shows the Raman spectra of graphene films grown by depositing the carbon films by arcing for different times (1-4 s) at $800^{\circ} \mathrm{C}$ and annealing in the hydrogen gas at same temperature (as shown in Fig. 2). A significant change was found in the shape and intensity of the different bands (D, G, and 2D bands) when the arc time was increased from 1 to $4 \mathrm{~s}$. Figure 4(a) represents a very small D band in the graphene film grown for the arc time of $1 \mathrm{~s}$ whose intensity slightly increased with increasing the arc time. Similarly, the intensity of $\mathrm{G}$ band increased and 2D band decreased, respectively, with the increase in the arc time from 1 to $4 \mathrm{~s}$. It is of great significance to emphasize that the intensity of D band is very small in the deposited graphene films. Fundamentally, the defect in the graphene film is generated at the grain boundary of the substrate. During the growth of graphene films at high temperature $\left(800^{\circ} \mathrm{C}\right)$ on $\mathrm{Ni} / \mathrm{SiO}_{2} / \mathrm{Si}$, carbon atoms get dissolved within the nickel film and precipitate out on the surface of nickel as the film is cooled. The carbon atoms precipitate on the nickel grain boundary that does not form the symmetrical hexagonal bond in the graphene film and acts as disorder in the films. In the present work, the substrate $\mathrm{Ni} / \mathrm{SiO}_{2} / \mathrm{Si}$ was annealed at $800{ }^{\circ} \mathrm{C}$ before arcing (depositing carbon) in the presence of hydrogen, which substantially eliminated the surface oxygen, resulting in the increased grain size and decreased number of grain boundary in the film. Moreover, the increase in the D band intensity in the film deposited for larger arc time might be due to the defect related interaction between the layers in graphene. It was found that the position of D band shifts from the 1349.3 to $1352.4 \mathrm{~cm}^{-1}$. Additionally, the position of $\mathrm{G}$ band shifts from 1582.4 to $1578.1 \mathrm{~cm}^{-1}$ upon increasing the arc time. Similarly, it was observed that the $2 \mathrm{D}$ band right shifted from 2688.5 to $2703.8 \mathrm{~cm}^{-1}$ with the change in the arc time. The $2 \mathrm{D}$ band of Raman spectra of graphene prepared for $2 \mathrm{~s}$ arc time is shown in Fig. 4(b) and was fitted with the four Lorentzian peaks. In the literature, it has been explained that four component peaks' fit is possible only in the bilayer graphene, because the interaction of planes causes the $\pi$ and $\pi^{*}$ bands to divide in four, with a different splitting for electron and hole. Figures 4(c) and 4(d) show the value of $\mathrm{I}_{2 \mathrm{D}} / \mathrm{I}_{\mathrm{G}}$ and FWHM $_{2 \mathrm{D}}$ versus arc time. The value of $\mathrm{I}_{2 \mathrm{D}} / \mathrm{I}_{\mathrm{G}}$ decreases from 3.82 to 0.38 , and the value of $\mathrm{FWHM}_{2 \mathrm{D}}$ increases from 41 to $70 \mathrm{~cm}^{-1}$ as the arc time increases from 1 to $4 \mathrm{~s}$. All the Raman results are summarized in Table I. It has been reported by other groups ${ }^{32,33}$ that the value of $\mathrm{I}_{2 \mathrm{D}} / \mathrm{I}_{\mathrm{G}}$ of $>2.5$ corresponds to single layer graphene and bi- or trilayer and a few layer graphene has the value of $\mathrm{I}_{2 \mathrm{D}} / \mathrm{I}_{\mathrm{G}}$ as $\sim 1$ and 0.5 , respectively. Similarly, it was reported that single, bi- or triand a few layer graphene have the value of $\mathrm{FWHM}_{2 \mathrm{D}}$ as $\sim 30-40,42-50$, and $55-60 \mathrm{~cm}^{-1}$, respectively. Eventually,

TABLE I. Values of various peak positions of the Raman spectra of prepared graphene films at $800^{\circ} \mathrm{C}$ for different arc times.

\begin{tabular}{|c|c|c|c|c|c|c|c|}
\hline S. no. & Time of arcing (s) & D peak position $\left(\mathrm{cm}^{-1}\right)$ & G peak position $\left(\mathrm{cm}^{-1}\right)$ & 2D peak position $\left(\mathrm{cm}^{-1}\right)$ & $\mathrm{I}_{\mathrm{D}} / \mathrm{I}_{\mathrm{G}}$ & $\mathrm{I}_{2 \mathrm{D}} / \mathrm{I}_{\mathrm{G}}$ & $\mathrm{FWHM}_{2 \mathrm{D}}\left(\mathrm{cm}^{-1}\right)$ \\
\hline 1 & 1 & 1349.3 & 1582.4 & 2688.5 & 0.16 & 3.82 & 41 \\
\hline 2 & 2 & 1352.5 & 1583.4 & 2698.8 & 0.16 & 1.17 & 49 \\
\hline 3 & 3 & 1351.4 & 1579.3 & 2700.5 & 0.15 & 0.55 & 61 \\
\hline 4 & 4 & 1352.4 & 1578.1 & 2703.8 & 0.16 & 0.38 & 70 \\
\hline
\end{tabular}


it might be comprehended that the graphene films prepared for $1 \mathrm{~s}$ arc time has a single layer. Similarly, the graphene films prepared for 2, 3, and $4 \mathrm{~s}$ arc time has bi- or trilayer, four or five layers, and multilayer growth. The results of different layer graphene growth elucidated from the Raman spectra have been correlated with the HRTEM results, which exhibit the growth of single, bi- or tri-, and multilayer graphene with the increase in arc time for 1-4s.

\section{High resolution transmission electron microscopy}

The thickness control and uniformity of the prepared graphene films were investigated by the HRTEM. Figure 5 shows the HRTEM micrographs of graphene films prepared for different arc times $(1,2$, and $3 \mathrm{~s})$ at $800^{\circ} \mathrm{C}$ substrate temperature. In-depth microstructural investigations on graphene films elucidated interesting features at nanoscale. It was found that the suspended graphene films on the TEM grid are continuous over a large area. Figure 5(a) represents the micrograph of graphene film prepared for $1 \mathrm{~s}$ arc time. Arbitrarily selected graphene edge shows only one carbon layer, which affirms the single layer characteristic of the prepared graphene film. In the inset of Fig. 5(a), the selected area electron diffraction pattern of graphene film prepared for $1 \mathrm{~s}$ arc time clearly shows the typical hexagonal crystalline structure (sixfold symmetric pattern) of graphene as described in the growth model (Fig. 3). Moreover, Figs. 5(b) and 5(c) show the graphene films prepared at $2 \mathrm{~s}$ arc time. These low magnification micrographs precisely reveal the bi- or trilayer nature of the films, which are easily distinguishable. Similarly, Fig. 5(d) shows the HRTEM micrograph of four or five layered graphene film prepared for $3 \mathrm{~s}$ arc time. Furthermore, the separation between the graphene layers was determined as $0.34 \mathrm{~nm}$. Thus, it may be comprehended that the HRTEM exhibits a very clear separation in the different layers of graphene films prepared at different arc times. The number of layers estimated from the HRTEM study in the graphene films are found to be well correlated with the number of layers as observed in the Raman study.

\section{E. Optical microscopy}

It has been described that the graphene films of different layers can be visualized on top of the silicon wafer with a certain thickness of $\mathrm{SiO}_{2}$ using optical microscopy and these strongly depend on the thickness of $\mathrm{SiO}_{2}$ and illuminated light wavelength. The visualization is fundamentally based on the optical contrast, which appears due to not only by an increased optical path but also by the increased significant percentage of opacity in the graphene. The optical contrast $\mathrm{C}$ (Ref. 34) is defined as the relative intensity of reflected light in the presence $\left(n_{1} \neq 1\right)$ and absence $\left(n_{1}=n_{0}=1\right)$ of graphene, $C=I\left(n_{1}=1\right)-I\left(n_{1}\right) / I\left(n_{1}=1\right)$, where $n_{0}$ and $n_{1}$ is the refractive index of air and graphene, respectively. ${ }^{35}$ Figure 6 shows the optical micrographs of graphene films prepared for arc time of (a) $1 \mathrm{~s}$, (b) $2 \mathrm{~s}$, and (c) $3 \mathrm{~s}$ at $800^{\circ} \mathrm{C}$. The graphene films were transferred on a $\mathrm{Si}$ wafer with a $400 \mathrm{~nm}$ thick $\mathrm{SiO}_{2}$ layer. It was assumed that the light is incident normally onto the trilayer structure consisting of graphene, $\mathrm{SiO}_{2}$, and $\mathrm{Si}$. Qualitatively, it might be observed from Fig. 6 that the value of contrast increases as the number of layers in graphene increases from the single layer to multilayers. In Fig. 6, some black spot is also observed due to the presence of PMMA residue. Ni et al. ${ }^{36}$ has also determined the thickness of graphene films by the reflection and contrast spectroscopy.

\section{F. Atomic force microscope}

Figure 7 shows the AFM image of graphene film prepared for $1 \mathrm{~s}$ arc time at $800^{\circ} \mathrm{C}$ substrate temperature. It indicates that the sample consists of only a single layer graphene. Some residues of nanometer dimension of PMMA on the surface of the graphene sheet visible in the image created the roughness in the graphene. Sometimes the patches of PMMA remain even after thorough rinsing in the acetone and subsequently in the distilled water, which may give rise to the thickness variation in the film. The corresponding cross section profile of graphene is also shown in the same figure. The wrinkling is a major problem in graphene, which is generated possibly due to the polymer used for the transfer of graphene film or if the polymer is not completely removed during transfer. It is also stuck and thin film gets wrinkled. The height profile of the single layer graphene may be corroborated with the Raman spectra of the single layer graphene, as shown in Fig. 4(a).

\section{SUMMARY}

In summary, graphene films have been deposited by the FCVA technique and its number of layers was determined.

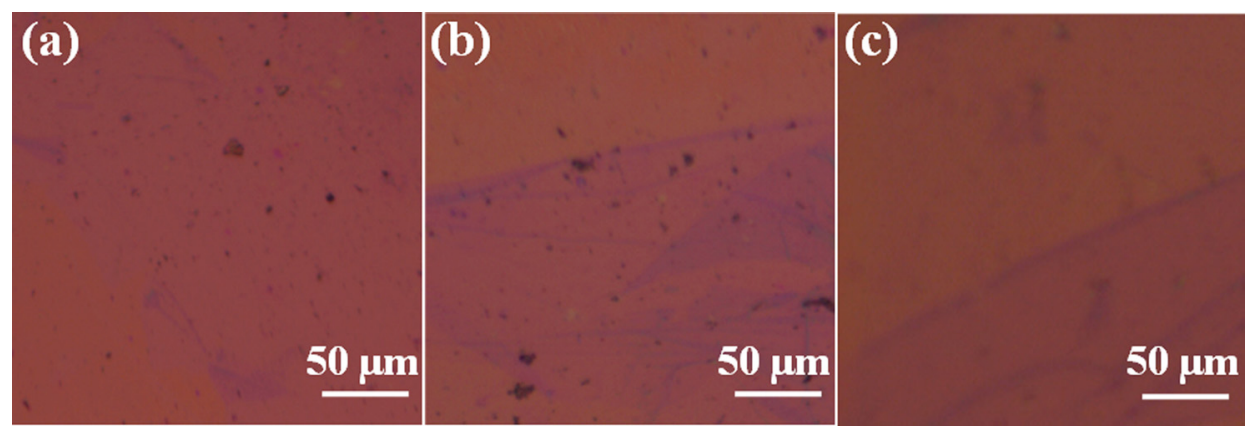

FIG. 6. (Color online) Optical image of graphene films prepared at $800^{\circ} \mathrm{C}$ for different arc times of (a) $1 \mathrm{~s}$, (b) $2 \mathrm{~s}$, and (c) $3 \mathrm{~s}$. 

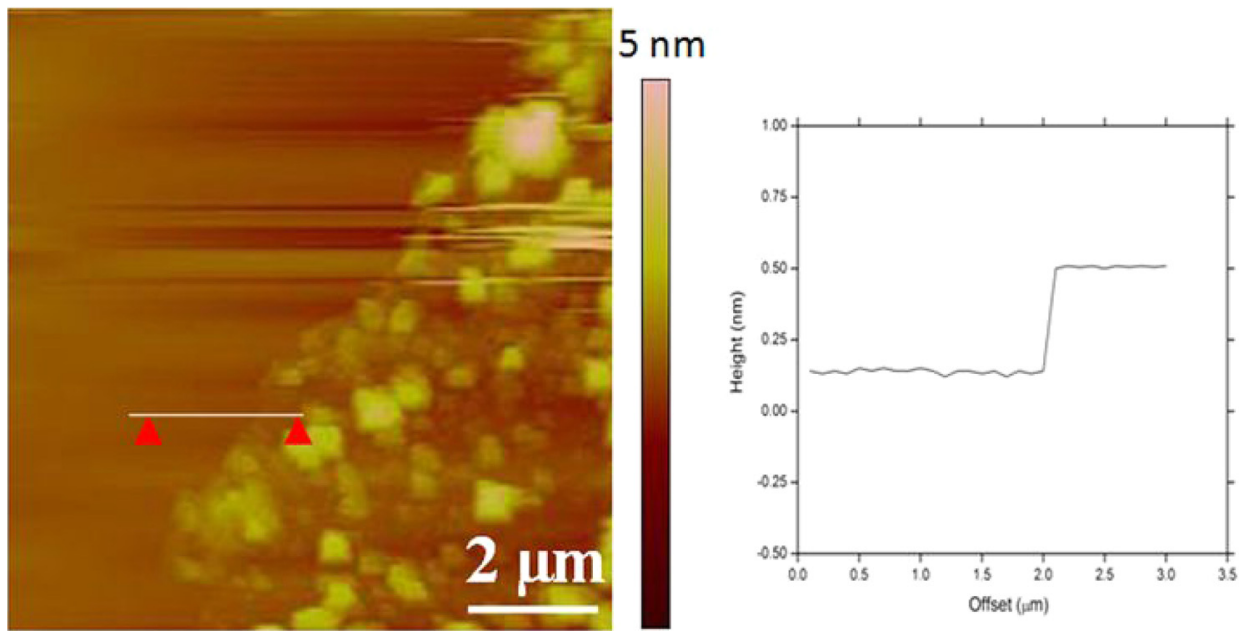

Fig. 7. (Color online) AFM image of graphene film prepared at $800^{\circ} \mathrm{C}$ for $1 \mathrm{~s}$ arc time.

The graphene films were grown by depositing carbon at different arc times (1-4s), and subsequently, the $\mathrm{C} / \mathrm{Ni} / \mathrm{SiO}_{2} / \mathrm{Si}$ substrates were annealed at $800^{\circ} \mathrm{C}$ and finally cooled to room temperature naturally in the presence of hydrogen gas. The as prepared graphene films were characterized by various techniques. Raman spectra of the prepared graphene films has exhibited that $\mathrm{G}$ peak changes from 1582.4 to $1578.1 \mathrm{~cm}^{-1}$, 2D peak shifts from 2688.5 to $2703.8 \mathrm{~cm}^{-1}$, the value of $\mathrm{I}_{2 \mathrm{D}} /$ $\mathrm{I}_{\mathrm{G}}$ increased from 0.38 to 3.82 , and full width at half maxima of $2 \mathrm{D}$ peak changes from 41 to $70 \mathrm{~cm}^{-1}$, for different layers of graphene films. It was observed by the HRTEM image that the graphene films prepared by 1 and $2 \mathrm{~s}$ arc time has single and bi- or trilayered structures. Conclusively, it was demonstrated that the FCVA technique has a great potential to grow high quality and layer controlled graphene films on large areas.

\section{ACKNOWLEDGMENTS}

The authors are grateful to the Director, CSIR-National Physical Laboratory, New Delhi (India), for his kind permission to publish this paper. They wish to thank Kamal Jeet and Anil Kumar of CSIR-CEERI, Pilani, for growing $\mathrm{SiO}_{2}$ layer on $\mathrm{Si}$ wafer and to Sandeep Singh for providing the AFM image. A. K. Kesarwani and Atul Bisht are grateful to the Council of Scientific Industrial Research (CSIR) and University Grant Commission (UGC), Government of India, respectively, for their financial assistance during the course of this work. Ashish Kumar is grateful to the Ministry of Science and Technology, Government of India, for the financial assistance during the course of this work.

${ }^{1}$ K. S. Novoselov, A. K. Geim, S. V. Morozov, D. Jiang, Y. Zhang, S. V. Dubonos, I. V. Grigorieva, and A. A. Firsov, Science 306, 666 (2004).

${ }^{2}$ J. Yang, J. W. Kim, and H. S. Shin, Adv. Mater. 24, 2299 (2012).

${ }^{3}$ T. H. Han, Y. Lee, M. R. Choi, S. H. Woo, S. H. Bae, B. H. Hong, J. H.

Ahn, and T. W. Lee, Nat. Photonics 6, 105 (2012).

${ }^{4}$ X. An, F. Liu, and S. Kar, Carbon 57, 329 (2013).
${ }^{5}$ K. S. Novoselov, A. K. Geim, S. V. Morozov, D. Jiang, M. I. Katsnelson, I. V. Grigorieva, S. V. Dubonos, and A. A. Firsov, Nature 438, 197 (2005).

${ }^{6}$ C. Lee, X. Wei, J. W. Kysar, and J. Hone, Science 321, 385 (2008).

${ }^{7}$ K. S. Kim et al., Nature 457, 706 (2009).

${ }^{8} \mathrm{X}$. Li et al., Science 324, 1312 (2009).

${ }^{9}$ S. Stankovich, D. A. Dikin, R. D. Piner, K. A. Kohlhaas, A. Kleinhammes, Y. Jia, Y. Wu, S. T. Nguyen, and R. S. Ruoff, Carbon 45, 1558 (2007).

${ }^{10}$ A. Reina, X. Jia, J. Ho, D. Nezich, H. Son, V. Bulovic, M. S. Dresselhaus, and J. Kong, Nano Lett. 9, 30 (2009).

${ }^{11}$ G. W. Cushing, V. Johánek, J. K. Navin, and I. Harrison, J. Phys. Chem. C 119, 4759 (2015).

${ }^{12}$ X. Fei, L. Zhang, W. Xiao, H. Chen, Y. Que, L. Liu, K. Yang, S. Du, and H. J. Gao, J. Phys. Chem. C 119, 9839 (2015).

${ }^{13}$ A. Dahal, R. Addou, P. Sutter, and M. Batzill, Appl. Phys. Lett. 100, 241602 (2012).

${ }^{14}$ T. H. R. Cunha, J. E. Weis, R. G. Lacerda, and A. S. Ferlauto, Appl. Phys. Lett. 105, 073104 (2014).

${ }^{15}$ G. Pana, B. Li, M. Heath, D. Horsell, M. L. Wears, L. A. Taan, and S. Awan, Carbon 65, 349 (2013).

${ }^{16}$ W. Zhang, P. Wu, Z. Li, and J. Yang, J. Phys. Chem. C 115, 17782 (2011).

${ }^{17}$ A. K. Kesarwani, O. S. Panwar, S. Chockalingam, A. Bisht, S. R. Dhakate, B. P. Singh, A. K. Srivastava, and R. K. Rakshit, Sci. Adv. Mater. 6, 2124 (2014).

${ }^{18}$ O. S. Panwar, A. K. Kesarwani, S. R. Dhakate, B. P. Singh, R. K. Rakshit, A. Bisht, and S. Chockalingam, J. Vac. Sci. Technol. B 31, 040602 (2013).

${ }^{19}$ J. Robertson, Mater. Sci. Eng. R 37,129 (2002).

${ }^{20}$ O. S. Panwar, M. A. Khan, M. Kumar, S. M. Shivaprasad, B. S. Satyanarayana, P. N. Dixit, and R. Bhattacharya, Jpn. J. Appl. Phys. 48, 065501 (2009).

${ }^{21}$ O. S. Panwar, S. K. Gupta, M. A. Khan, B. S. Satyanarayana, and R. Bhattacharyya, Diamond Relat. Mater. 13, 513 (2004).

${ }^{22}$ O. S. Panwar, M. A. Khan, R. Bhattacharyya, B. R. Mehta, S. Kumar, Ishpal, and B. S. Satyanarayana, J. Vac. Sci. Technol. B 28, 411 (2010).

${ }^{23}$ O. S. Panwar, M. A. Khan, G. Bhagawanarayana, P. N. Dixit, S. Kumar, and C. M. S. Rauthan, Indian J. Pure Appl. Phys. 46, 797 (2008).

${ }^{24}$ A. Anders, W. Fong, A. V. Kulkarni, F. W. Ryan, and C. S. Bhatia, IEEE Trans. Plasma Sci. 29, 768 (2001).

${ }^{25}$ K. Fujita, K. Banno, H. R. Aryal, and T. Egawa, Appl. Phys. Lett. 101, 163109 (2012).

${ }^{26}$ I. G. Brown, Annu. Rev. Mater. Sci. 28, 243 (1998).

${ }^{27}$ Vacuum Arc Science and Technology, edited by R. L. Boxman, P. J. Martin, and D. M. Sanders (Noyes, NJ, 1995), pp. 208.

${ }^{28}$ J. Lahiri, T. Miller, L. Adamska, I. I. Oleynik, and M. Batzill, Nano Lett. 11, 518 (2011).

${ }^{29}$ L. Meng, Q. Sun, J. Wang, and F. Ding, J. Phys. Chem. C 116, 6097 (2012). 
${ }^{30}$ P. Wu, Y. Zhang, P. Cui, Z. Li, J. Yang, and Z. Zhang, Phys. Rev. Lett. 114, 216102 (2015).

${ }^{31}$ A. C. Ferrari and D. M. Basko, Nat. Nanotechnol. 8, 235 (2013).

${ }^{32}$ R. Saito, M. Hofmann, G. Dresselhaus, A. Jorio, and M. S. Dresselhaus, Adv. Phys. 60, 413 (2011).

${ }^{33}$ A. Gupta, G. Chen, P. Joshi, S. Tadigadapa, and P. C. Eklund, Nano Lett. 6, 2667 (2006).
${ }^{34}$ R. R. Nair, P. Blake, A. N. Grigorenko, K. S. Novoselov, T. J. Booth, T. Stauber, N. M. R. Peres, and A. K. Geim, Science 320, 1308 (2008).

${ }^{35}$ P. Blake, E. W. Hill, A. H. Castroneto, K. S. Nevoselov, D. Jiang, R. Yang, T. J. Booth, and A. K. Geim, Appl. Phys. Lett. 91, 063124 (2007).

${ }^{36}$ Z. H. Ni, H. M. Wang, J. Kasim, H. M. Fan, T. Yu, Y. H. Wu, Y. P. Feng, and Z. X. Shen, Nano Lett. 7, 2758 (2007). 